\title{
Single-Electron Oxidation of Monomeric Copper (I) Alkyl Complexes: Evidence for Reductive Elimination through Bimolecular Formation of Alkanes
}

Laurel A. Goj ${ }^{\dagger}$, Elizabeth D. Blue ${ }^{\dagger}$, Samuel A. Delp ${ }^{\dagger}$, T. Brent Gunnoe ${ }^{\dagger *}$, Thomas R. Cundari $^{\ddagger}$ and Jeffrey L. Petersen ${ }^{\S}$

${ }^{\dagger}$ Department of Chemistry, North Carolina State University, Raleigh, NC 27695-8204; ${ }^{\ddagger}$ Center for Advanced Scientific Computing and Modeling (CASCaM), Department of Chemistry, University of North Texas, Box 305070, Denton, TX, 76203-5070; ${ }^{\S} \mathrm{C}$. Eugene Bennett Department of Chemistry, West Virginia University, Morgantown, WV 26506-6045 


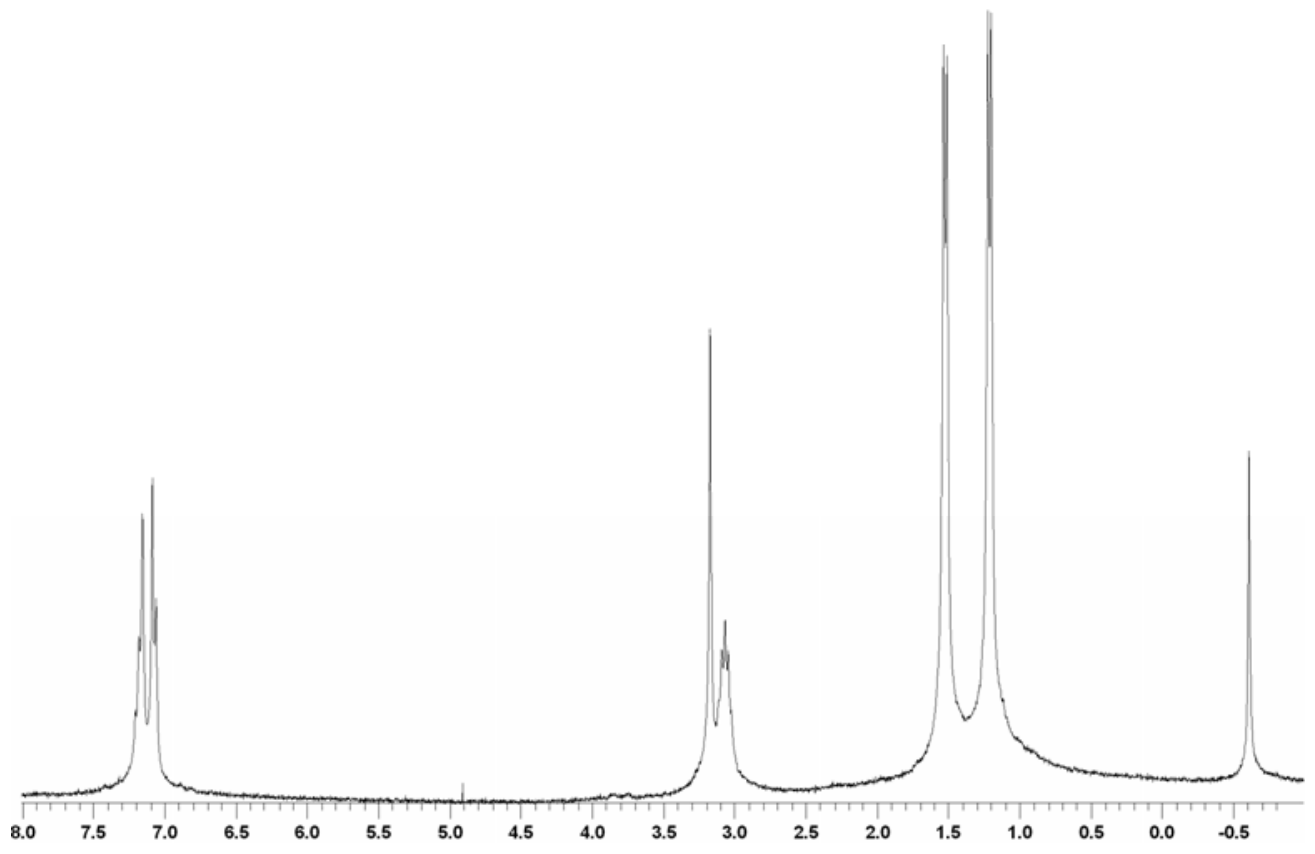

Figure S1. ${ }^{1} \mathrm{H}$ NMR spectrum of (SIPr)Cu(Me) (3) at $22{ }^{\circ} \mathrm{C}$ in $\mathrm{C}_{6} \mathrm{D}_{6}$.

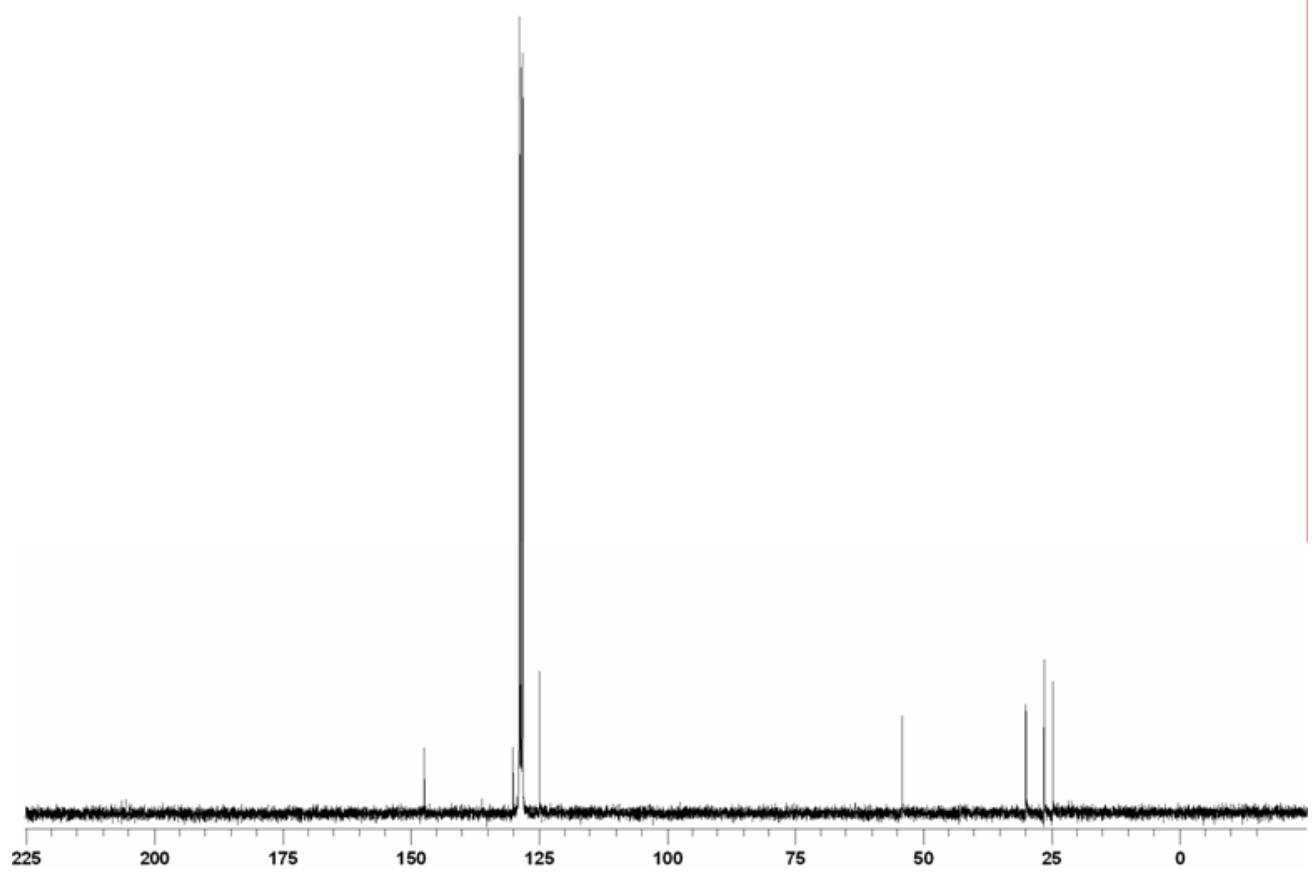

Figure S2. ${ }^{13} \mathrm{C}$ NMR spectrum of (SIPr)Cu(Me) (3) at $22{ }^{\circ} \mathrm{C}$ in $\mathrm{C}_{6} \mathrm{D}_{6}$. 


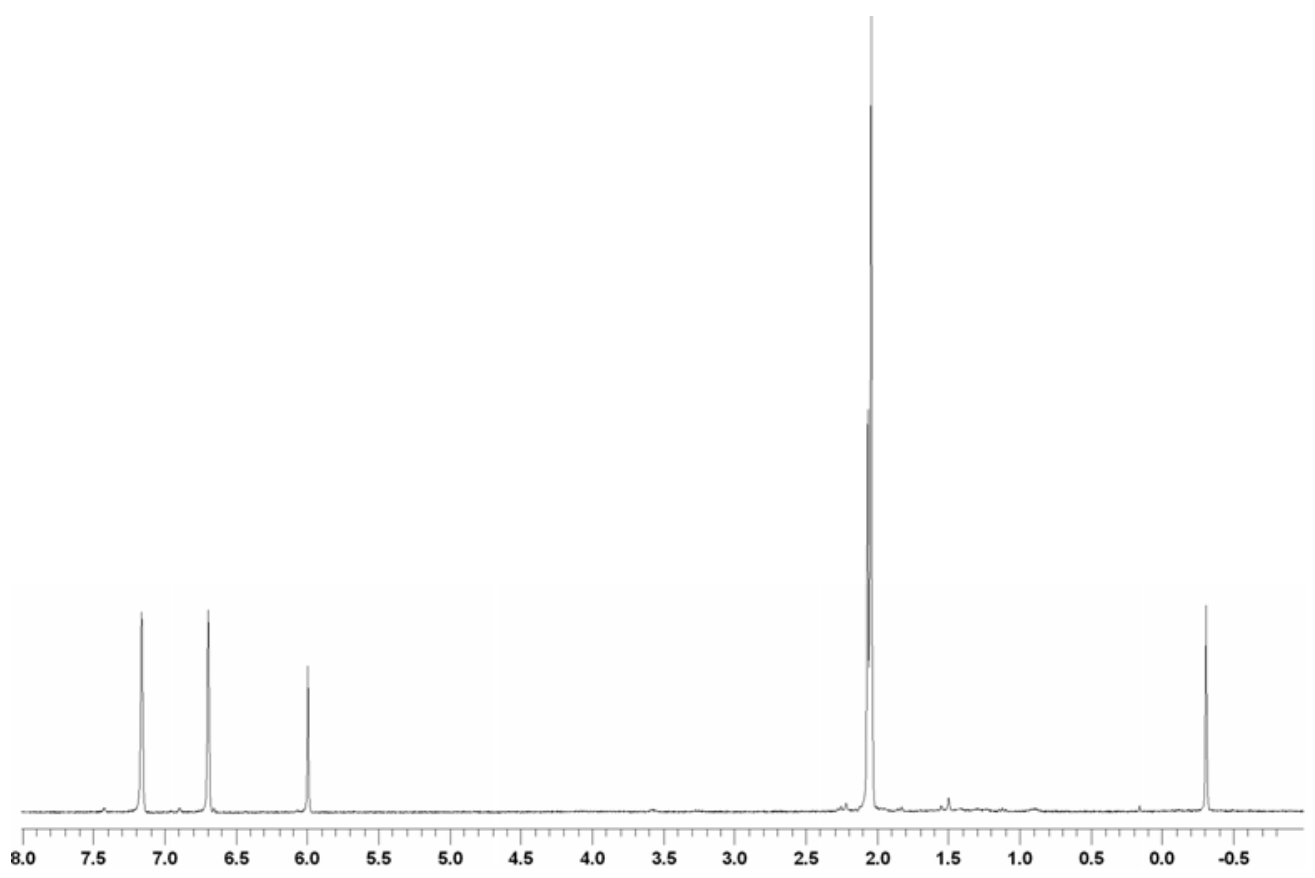

Figure S3. ${ }^{1} \mathrm{H}$ NMR spectrum of (IMes)Cu(Me) (4) at $22{ }^{\circ} \mathrm{C}$ in $\mathrm{C}_{6} \mathrm{D}_{6}$.

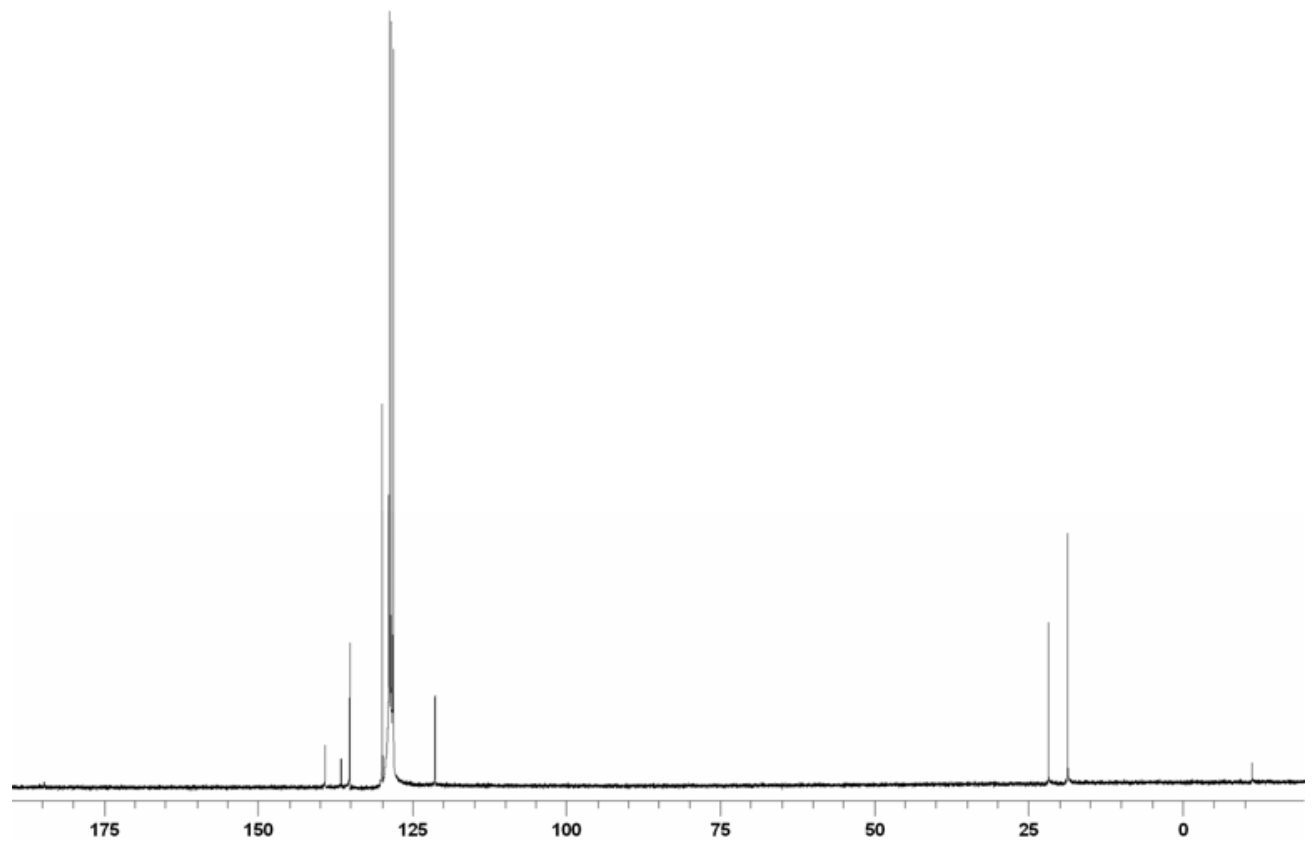

Figure S4. ${ }^{13} \mathrm{C}$ NMR spectrum of (IMes) $\mathrm{Cu}(\mathrm{Me})(\mathbf{4})$ at $22{ }^{\circ} \mathrm{C}$ in $\mathrm{C}_{6} \mathrm{D}_{6}$. 


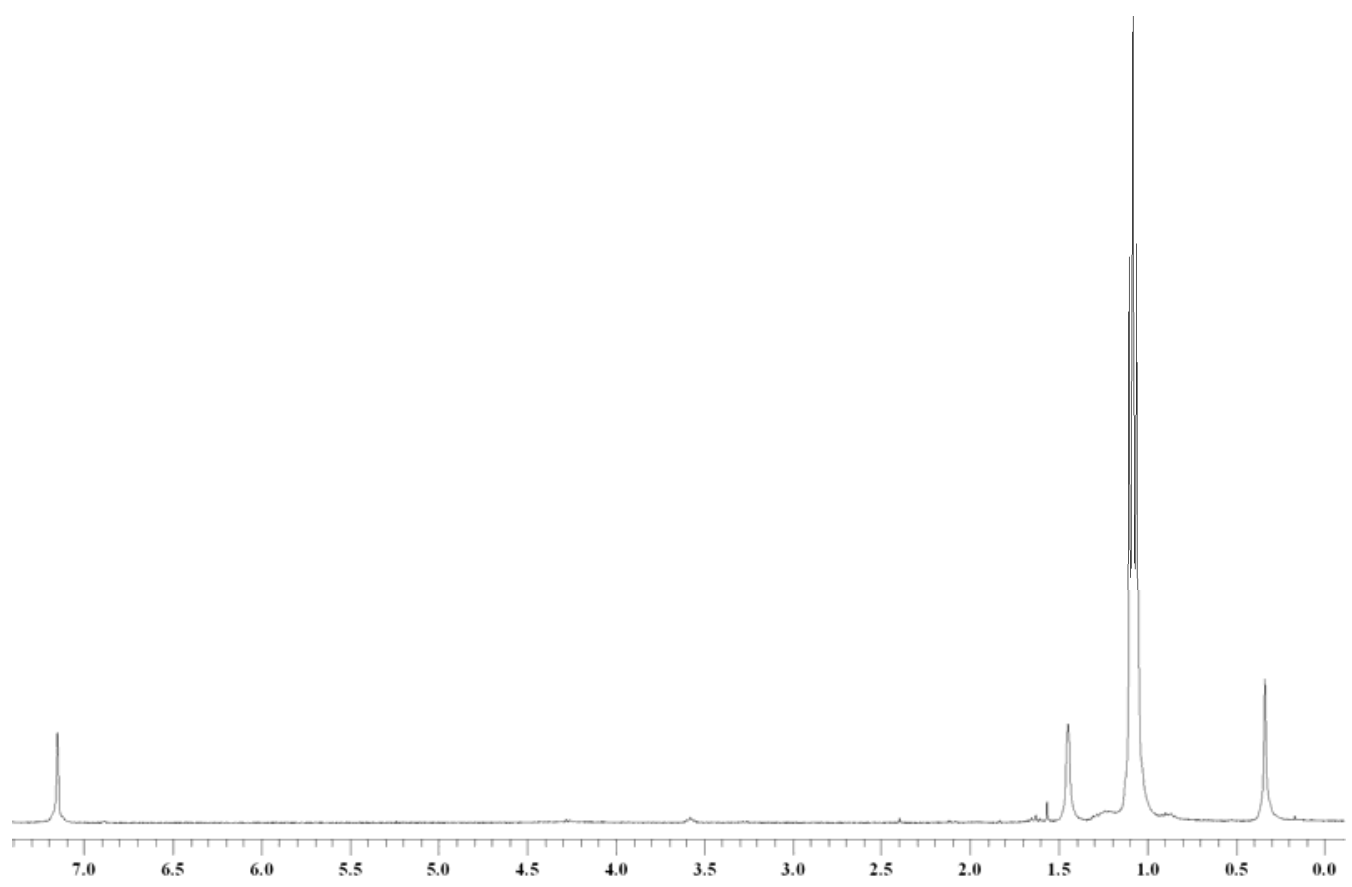

Figure S5. ${ }^{1} \mathrm{H}$ NMR spectrum of (dtbpe)Cu(Me) (6) at $22{ }^{\circ} \mathrm{C}$ in $\mathrm{C}_{6} \mathrm{D}_{6}$.

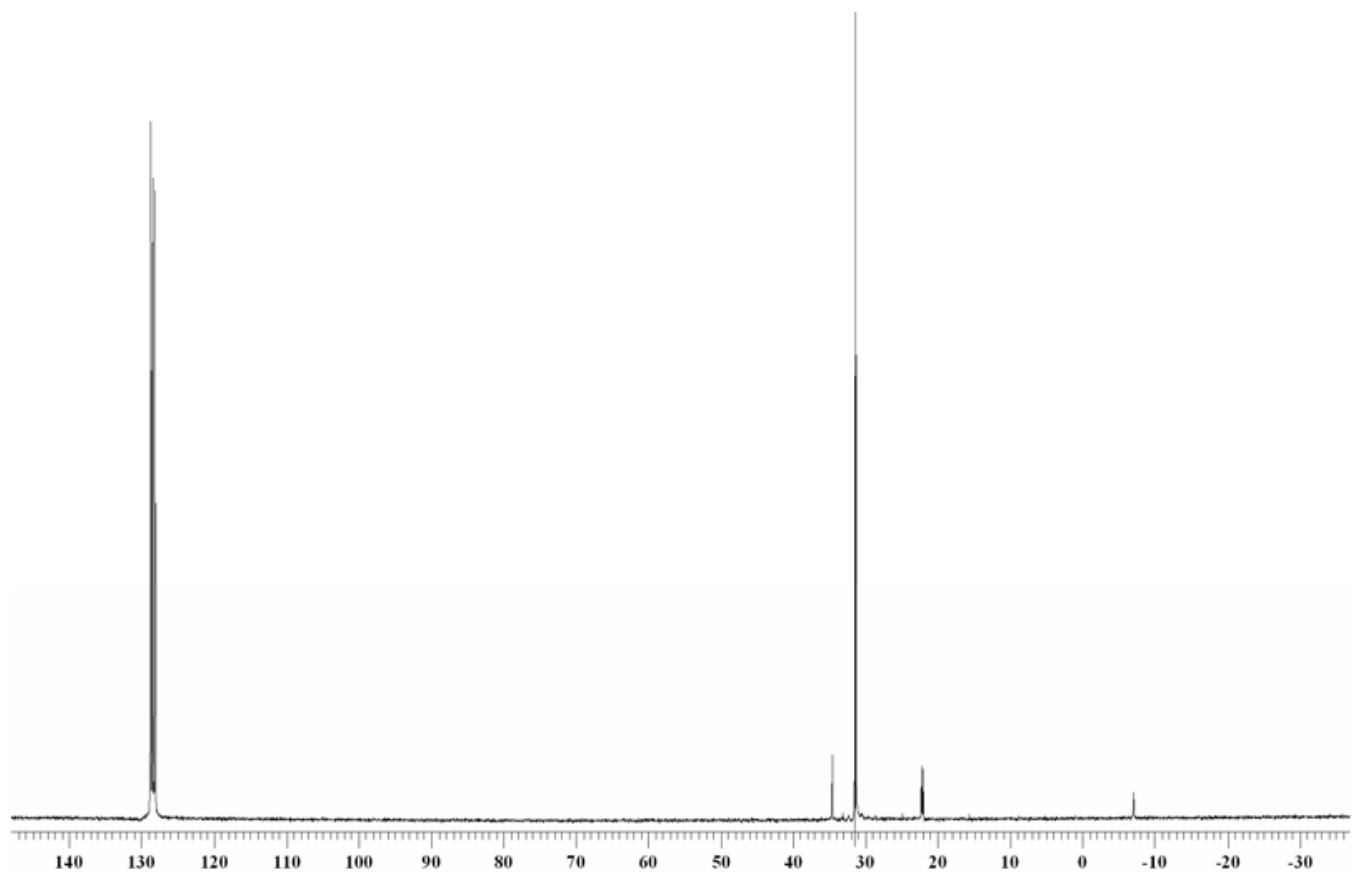

Figure S6. ${ }^{13} \mathrm{C}$ NMR spectrum of (dtbpe)Cu(Me) (6) at $22{ }^{\circ} \mathrm{C}$ in $\mathrm{C}_{6} \mathrm{D}_{6}$. 


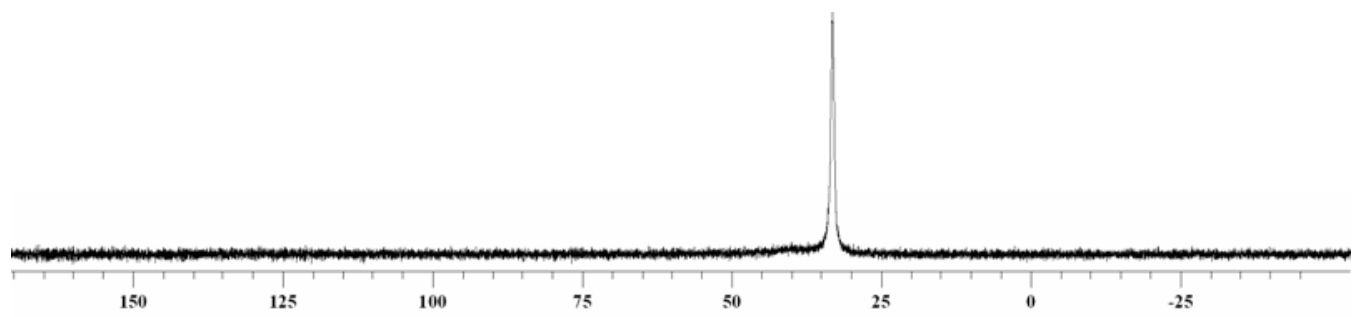

Figure S7. ${ }^{31} \mathrm{P}$ NMR spectrum of (dtbpe)Cu(Me) (6) at $22{ }^{\circ} \mathrm{C}$ in $\mathrm{C}_{6} \mathrm{D}_{6}$. 